\title{
Datastorming: Crafting Data into Design Materials for Design Students' Creative Data Literacy
}

\author{
Delia Yi Min Lim \\ National University of Singapore \\ delialim@u.nus.edu
}

\author{
Christine Ee Ling Yap \\ National University of Singapore \\ christine.yap@u.nus.edu
}

\author{
Jung-Joo Lee \\ National University of Singapore \\ jjlee@nus.edu.sg
}

\begin{abstract}
With the wave of data-driven design, data literacy is increasingly important for designers, so current design education aims to incorporate data literacy. However, designing with data can be challenging to design students as it might appear more abstract than tangible. In this research, we explore how design students could build creative data literacy by materializing data into tangible card formats, to inform their ideation process. We developed a method called Datastorming for design students to learn to create new design concepts using various data sets. Datastorming was tested in a university's service design course with 23 undergraduate students. Results show that Datastorming helped the students physically interact with various data sets to create meaningful connections and contextualize data for possible use scenarios. We discuss how Datastorming supports the designerly way of using data and helps students build creative data literacy for their design work.
\end{abstract}

\section{CCS CONCEPTS}

- Human-centered computing; • Human computer interaction (HCI); • HCI design and evaluation methods;

\section{KEYWORDS}

Data literacy, data-driven design, design game, service design

\section{ACM Reference Format:}

Delia Yi Min Lim, Christine Ee Ling Yap, and Jung-Joo Lee. 2021. Datastorming: Crafting Data into Design Materials for Design Students' Creative Data Literacy. In Creativity and Cognition (C\&C '21), June 22, 23, 2021, Virtual Event, Italy. ACM, New York, NY, USA, 9 pages. https://doi.org/10.1145/ 3450741.3465246

\section{INTRODUCTION}

Utilization of data as a creative material in design work has been increasingly gaining traction due to the extensive datafication trends [24] following the 'big data boom' [26]. In Human Computer Interaction (HCI), the notion of Human-Data Interaction (HDI) has been introduced as a research theme to explore how users interact with and makes sense of large datasets [38, 43]. However, concepts and case studies of designing with open data or self-collected data, revealed that the substantial data involved can be daunting without data scientist collaborators or some level of technical knowledge

Permission to make digital or hard copies of part or all of this work for personal or classroom use is granted without fee provided that copies are not made or distributed for profit or commercial advantage and that copies bear this notice and the full citation on the first page. Copyrights for third-party components of this work must be honored

For all other uses, contact the owner/author(s).

C\&C '21, June 22, 23, 2021, Virtual Event, Italy

(C) 2021 Copyright held by the owner/author(s)

ACM ISBN 978-1-4503-8376-9/21/06.

https://doi.org/10.1145/3450741.3465246
$[15,20]$. In addition, working with data in the design process can be challenging for designers who have limited data literacy. Responding to this gap, there have been studies aiming to teach data literacy to students with various foci, involving data collection or data visualization $[2,41,42]$. There have also been studies that creatively teach data literacy, where data was used to explore narratives to convey meaningful messages [3] or engage communities to participate in social innovations [8].

Our research explores ways for design students to develop data literacy for their creative work, by materializing data into tangible card formats, to inspire and inform the creative ideation process. As the concept and forms of data can be abstract to design students, the main principle of our method development lies in supporting designers' genuine way of doing and thinking $[10,18]$, often dealing with tangible materials, gaining inspiration from and visualizing the outcomes through synthetic thinking and solution-oriented thinking. Rather than focusing on the technicalities involved in collecting, processing, and visualizing data, we crafted data into creative design materials, just as how paper, clay or wood are to designers in their design process. This might provide an entry point for design students to engage in data-driven design and build their interests and familiarity to the use of data in their design work. With a different focus than data physicalization [17], our work represented datasets in tangible card formats for hands-on exploration. While data could inform the various phases of the design process, our paper focuses on how data can be creatively used in the idea generation phase for new design concepts enabled by data, in other words, design concepts based on data [39].

In this paper, we firstly review the emerging roles of data in the design process, followed by the review of previous efforts to build data literacy relevant to the design practice. Then we introduce the development of a new method called "Datastorming" (Figure 1 ), where data is materialized into a set of tangible artifacts to support design student's hands-on thinking [16] and collaboration for creating new design concepts. While many existing studies on data literacy for design focus on data visualization or collection, Datastorming aims to boost the creative use of various types of data for the ideation process in design. We will discuss how the Datastorming method enables design students to deal with data as creative materials and discuss limitations and future directions.

\section{DATA IN DESIGN}

\subsection{Data in the design process}

How data can be used in the design process varies depending on the roles and types of data. There have been more than a few studies that attempt to clarify the different roles of data in the design process and the various design actions with data [5, 20, 39]. 


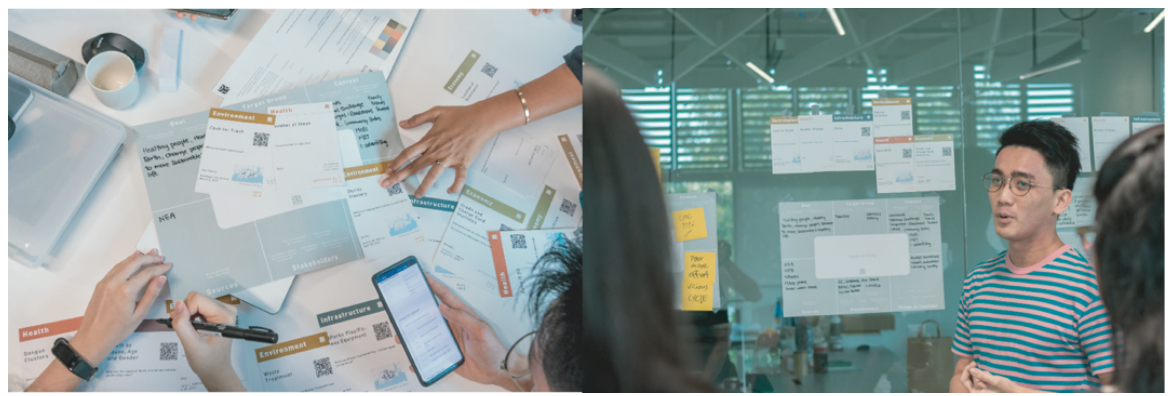

Figure 1: (left): Datastorming kit in the service design workshop; (right): A student presenting a service concept generated from Datastorming

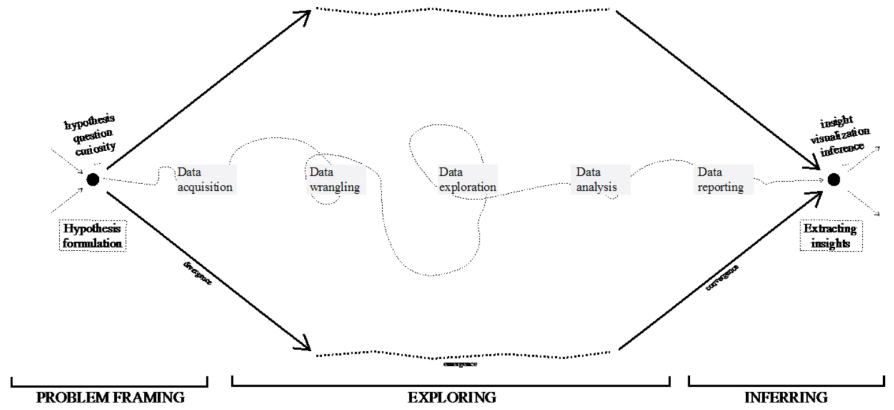

view of the Exploratory Data Inquiry Framework, combining a divergence-emergence-conve cts of data work [20]

Figure 2: The overview of the Exploratory Data Inquiry Framework, combining a divergence-emergence-convergence creative loop and related acts of data work [20]

When exploring how creativity can manifest in the early phase of designing with data, Kun et al. [20] propose an Exploratory Data Inquiry Framework (Figure 2), where designers are firstly led to re-frame ill-defined problems for exploration of potential design spaces in the early phase of the design process. According to Kun et al. [20], data acquisition is seen as the first step when designing with data. This can be done using pre-recorded data sets found on open sources or self-curated as part of the design process to meet the needs of the project. Next is data wrangling, which is to prepare the acquired data for analysis by ensuring consistency throughout. Following on is an open-ended data exploration, to understand the properties of the data and identify structures within. From this exploration, data analysis is done in a more focused manner where various characteristics and dimensions of the data are targeted. The last step is data reporting where the outcomes from the analysis are shared through boundary objects [21] such as visualizations.

There have been a few recent studies on clarifying the roles of data in designing services. Turki and Foulonneau [39] discuss three types of roles of data in the service design process, including 1) service based on data, 2) service using data as a resource, and 3) service validated or enriched with data, where the data is not directly used or is not directly visible in the service. According to them, service based on data focuses on the use of one or more data sets to design a service. Service using data as a resource considers data sets in investigating the feasibility of the service, even though the data sets may not have been the core for the service concept at the ideation phase. Service validation uses external data sets that are not in the service itself, to test the service concept or validate data held by the service designer [39].

Prendiville et al. [33] also discuss how service design plays a role in turning the abstract and intangible nature of data into humancentered services with social and economic values. The authors consider how service designers are able to make sense of data through translation, visualization and persuasion, thus transforming technical data into a new kind of resource that can be utilized by broader communities for service design. Both open data sources and self-collected data can be used in this transformation. With the emerging movement of open data [14, 28], some studies demonstrate that publicly available data sets could help generate new services and applications [29]. McBride et al. [27] explore how open government data can be used to break down barriers during co-creation with stakeholders and give rise to new public services. Similarly, Foulonneau et al. [15] review how opportunities such as hackathons, off-site competitions and calls for contribution could raise the awareness of developers and service creators on the potential of creating new services by reusing open data. For example, the reuse of "Singapore map (OneMap) data" data set led to the creation of 33 apps [15]. Conducting design inquiry with the use 
of self-collected data through data-collecting probes or sensors in everyday objects, on the other hand, is also a growing trend. Bogers et al. [4] look at the use of sensor data and contextual probes to gain insights for new design interventions in the interaction between parents and healthcare professionals. Marti et al. [25] take the opportunity of using data collected from experiential probes to address societal issues and design for social change. The abovementioned studies demonstrate how creative uses of open data or self-collected data can inform the creation of new interaction design and service concepts.

\subsection{Creative data literacy}

What data literacy means varies in different contexts, and it involves multiple levels of ability to be applied in various phases of the work. Bhargava et al. [3] propose a general definition of data literacy by referring it as "the ability to read, work with, analyze and argue with data”. In the design community, Götzen et al. [12] include collection and application of data in the required ability and defines data literacy as "the ability to collect, manage, evaluate, and apply data in a critical manner". There have been more than a few studies that explore ways to teach data literacy to students, be it by the critical questioning of self-collected or external data [42], by the use of participatory media to understand the impact of data in a mathematics curriculum [41] or by a tool that looks to improve students' ability to understand and interpret data through visualization [2].

The abovementioned studies show various efforts made to integrate data literacy into school curriculums. However, the existing approaches to teach data literacy emphasize technical skills, such as quantitative or qualitative data collection [22, 41, 42], or reading charts and making graphical visualization of data for interpretation $[2,28]$. Instead of these traditional techniques for technical data literacy, there has been a rise in methods for 'creative data literacy' as alternative techniques meant for non-technical learners to work with data. These techniques involve learners using open data or self-collected data that are relatable to them, exploring and physicalizing data beyond graphical representations, and creating narratives and contextualizing data for effective communication of their data-driven ideas [11].

Some recent studies show how creative data literacy is taught by using data for inspiration in various works. For example, Bhargava et al. [3] introduce an art-centric approach to teach creative data literacy, where students are inspired to draw murals based on the data they have collected. Students developed a critical awareness of user's actual situation and needs with the use of data, while building a relevant definition of the data analyzed within their context. Similarly, D'Ignazio [11] use data physicalization to teach how data can be creatively represented to create impacts on the issue of climate change. Their work shows how data can be taught, understood, and interpreted with a different visual language as compared to usual graphical methods.

Some work brings creative data literacy as part of co-design workshops. The work by Chueng-Nainby and Lee [8] is an apt example as they look to creatively use collective imagery as data to inspire social innovations. In their work, participants were engaged as a community to provide, collect, interact and make sense of data to inspire narratives and structures that highlight hidden elements in societal issues for generation of ideas and services. Through this, participants became aware of how data can inspire the restructuring of community's habits of mind and generate new social innovations and services.

\section{DEVELOPMENT OF METHOD: DATASTORMING}

Our study aims to explore ways to introduce creative data literacy to design students who have little experience on designing with data, besides user research findings as data for a human-centered design project. To overcome their unfamiliarity to data, we aimed to craft abstract data into hands-on design materials in the form of cards so that students can physically interact with the abstract concept and make sense of the data through hands-on thinking $[6,30]$. This section describes the development of the method called Datastorming.

\subsection{Datastorming kit}

The 'Datastorming kit' (see Figure 1) was inspired by notions of design game [40], a co-design setting where playfulness and game rules are applied to facilitate a collaborative and generative session. Vaajakallio and Mattelmäki [40] explain that interaction with tangible materials in design games supports visual manifestation of abstract concepts, perspectives, or ideas. Game settings and rules can enforce the players to act in a playful yet structured manner towards a shared goal. We tapped on the qualities of design games, such as tangible explorations of abstract concepts, negotiations of ideas, and playful rules and settings, when crafting abstract data into tangible materials to guide the creative process.

We chose the form of paper cards as a tangible medium containing data. Lucero et al. [23] encourage the use of cards as artefacts in design games due to its tangibility, familiarity, and modularity [6]. They also explained the effectiveness of the cards for turning intangible video sequences into tangible arguments for video analysis. For Datastorming, we created a set of Data Cards containing both open data and personal data. 40 types of open data were selected from Singapore's open data portal [36], based on the selection criteria of being understandable and relatable to students (not requiring expert domain knowledge) [3], and are more up-to-date.

To spark students' innovative ideas, we included 10 types of personal data, for students to explore combinations of open data and personal data (see Table 1). Other types of cards, such as 'Persona Cards' or 'Theme Cards', were also provided to inspire students with new possibilities and help them contextualize data for possible user/stakeholder groups and their desired values. In addition, the 'Data canvas' was included as a guided scaffold for students to structure and develop their ideas based on their selected data sets by considering goals, target users and related stakeholders, usage contexts, data sources, and ethics and data security (Figure 3, right). In this sense, the Data Cards are to support diverging thinking with data through data wrangling and exploration according to Kun et al. [20], and the Data Canvas is to support converging thinking through data analysis [20]. As results, the Datastorming kit consists of 50 Data Cards (40 open data sets and 10 personal data sets), 12 Persona Cards, 18 Theme Cards, and the Data Canvas (Table 1). 
Table 1: Components of the Datastorming kit

\begin{tabular}{|c|c|c|}
\hline Datastorming artefact & Purpose & Examples \\
\hline Open data cards $\mathrm{x} 40$ & $\begin{array}{l}\text { To support students' handling of open } \\
\text { data sets as tangible tinkering objects } \\
\text { for ideation and communication }\end{array}$ & $\begin{array}{l}7 \text { categories: Economy (e.g., credit and charge card statistics); } \\
\text { Education (e.g., graduate employment survey); Environment } \\
\text { (e.g., rainfall); Health (e.g., dengue clusters); Infrastructure (e.g., } \\
\text { parks); Society (e.g., key indicators of divorce); Transport (e.g., } \\
\text { carpark availability) }\end{array}$ \\
\hline Personal data cards x10 & $\begin{array}{l}\text { To encourage students to consider the } \\
\text { incorporation of personal data in the } \\
\text { service concept }\end{array}$ & $\begin{array}{l}3 \text { categories: Lifestyle (e.g., sleeping pattern); Health (e.g., heart } \\
\text { rate), Energy (e.g., electricity consumption) }\end{array}$ \\
\hline Persona cards x12 & $\begin{array}{l}\text { To help students identify potential } \\
\text { users/ stakeholders }\end{array}$ & $\begin{array}{l}\text { Caregiver, elderly, policy makers, parents, business owners, } \\
\text { educators, job seekers. . }\end{array}$ \\
\hline Theme cards x18 & $\begin{array}{l}\text { To help students contextualize the use } \\
\text { of data }\end{array}$ & $\begin{array}{l}\text { Energy saving, future planning, leisure, education, collaboration, } \\
\text { healthcare... }\end{array}$ \\
\hline Data canvas $\mathrm{x} 1$ & \multicolumn{2}{|c|}{$\begin{array}{l}\text { As a concept map [18] to guide the development of service ideas more holistically by encouraging the } \\
\text { consideration of connections between the goals, target users, stakeholders, usage contexts, data sources, } \\
\text { ethics, and data security }\end{array}$} \\
\hline
\end{tabular}

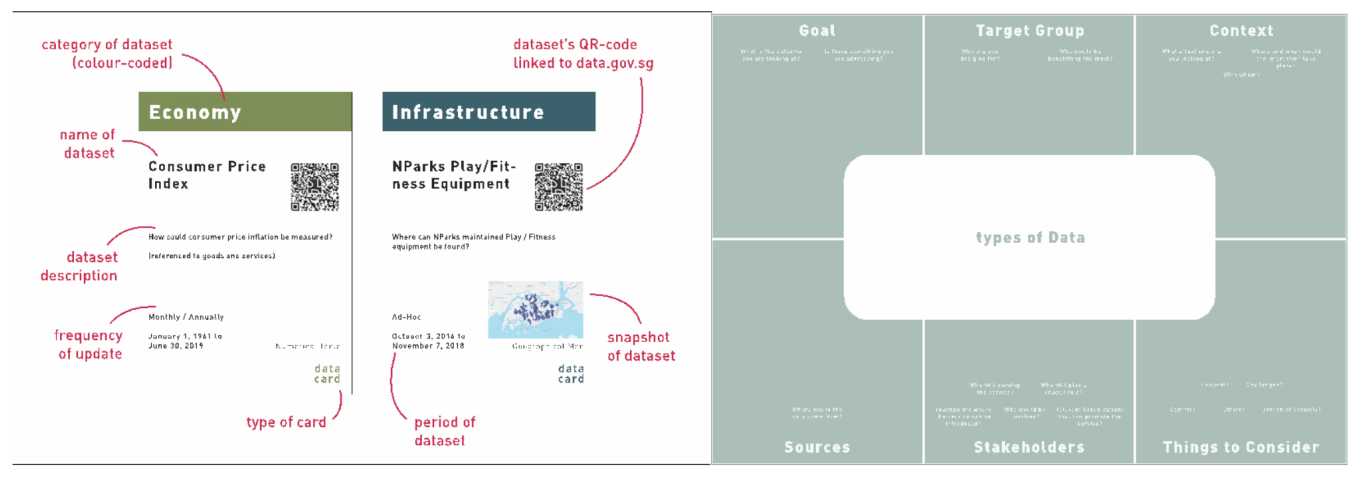

Figure 3: (left): Final design of the Data Card; (right): The Data Canvas for developing and presenting selected ideas.

To help students identify the types of data and its potential uses, each Data Card (Figure 3, left) presents the category in which the data set falls in (economy, infrastructure, health, etc.), the name of the data set itself with a short description, the period and frequency of data collection, and a snapshot of existing data visualizations (e.g. bar charts, maps) if available. We added a QR code to the original data source, for the students to easily go to the original source to explore more details.

We implemented the Datastorming as part of the service design course in the National University of Singapore. The service design course, "Design with Open Data", aimed to teach students creative data literacy and identify new service design opportunities enabled by open government data. The course was done in collaboration with the government agency who deals with open government data The agency's interest was to explore new opportunities benefitted from open government data, as they have not seen the active use and visibility of open government data despite its richness and variety. Undergraduate design students in this course had little experience on design based on data [39]. At the beginning of the course, we conducted the Datastorming workshop to provide the students with a hands-on and playful experience on what it is like to create new design ideas with data. 23 students and five government representatives participated in the workshop. The students were split into six teams of three or four, joined by one government representative each, except for one team. Six members from the tutoring group facilitated each student team. The Datastorming workshop consisted of two approaches, namely data-driven ideation and human-driven ideation, which are explained in Table 2.

Each student team played two rounds of the Datastorming, one with each approach. Each round lasted about 40 minutes. After both rounds, the students presented their ideas, followed by class discussions. During the sessions, the facilitators took observational notes on how the method facilitates group discussions and ideation. All 12 ideas presented by the students were also recorded for analysis. After the sessions, the facilitators shared their observational notes and discussed their findings. We also conducted two focus groups with the students to learn about their experiences with Datastorming. All interviews were transcribed for analysis. Authors analyzed the observational notes and interview transcripts together to elicit themes based on informed-grounded theory approach [6]. 
Table 2: Instructions for the data-driven ideation (Approach 1) and the human-driven ideation (Approach 2)

\begin{tabular}{|c|c|}
\hline Approach 1: Data-driven ideation & Approach 2: Human-driven ideation \\
\hline $\begin{array}{l}\text { This approach intends for students to directly delve into existing } \\
\text { data sets as primary source of inspiration, without placing early } \\
\text { restrictions on target users or contexts } \\
\text { Instructions: } \\
\text { 1. Shuffle the deck of Data Cards, randomly draw three cards and } \\
\text { think about: } \\
\text { a. Why is it interesting / relevant / important to you? } \\
\text { b. Who will be benefiting from it? } \\
\text { c. How can it be presented and delivered to people? } \\
\text { (You can combine open data and personal data cards.) } \\
\text { 2. Using the cards in your hand, ideate what services can be } \\
\text { designed and what it can be for? If you are unable to make a } \\
\text { connection with the cards in your hand, draw another Data Card(s). } \\
\text { 3. Use the QR code to know where the Data Source is from and } \\
\text { search for more information relevant to the data card. } \\
\text { 4. Present your ideas to your team members. } \\
\text { 5. If you find better connection with the cards from your } \\
\text { team-mate's hand, discuss and trade. (You can also create new Data } \\
\text { Cards by writing new types of data on the Blank Cards provided.) } \\
\text { 6. Within your team, pick one idea to develop. } \\
\text { 7. Place the chosen Data Cards and Persona-Theme Cards (only for } \\
\text { 1. Goal (What do you want to achieve?) } \\
\text { 2. Target Group (Who is this service for? Who will benefit? Would t } \\
\text { 3. Context (Where should this service be provided? Where and whe } \\
\text { 4. Sources (Where would the data come from?) } \\
\text { 5. Stakeholders (Beside the end-users, who will be involved and coll }\end{array}$ & $\begin{array}{l}\text { Similar to the convention Human-Centered Design process, this } \\
\text { approach starts with identifying potential target users and themes } \\
\text { to design for. } \\
\text { Instructions: } \\
\text { 1. Browse the Persona cards and pick one or two cards that you } \\
\text { want to design for. If you cannot find the Persona Card you want to } \\
\text { design for, use Blank cards and write your own keywords. } \\
\text { 2. Randomly pick one Theme Card and think of the connections } \\
\text { between your persona and theme. } \\
\text { 3. If you cannot make any connection between the two, you can } \\
\text { browse the Theme Cards and pick one that you see a meaningful } \\
\text { connection. If you cannot find the theme you want to design for, } \\
\text { use the Blank Cards and write your own keywords } \\
\text { 4. Explain to your team members why you think the pair of your } \\
\text { Persona and Theme cards would be meaningful. } \\
\text { 5. Within your team, pick one pair of persona-theme you want to } \\
\text { design for. } \\
6 . \text { Place the card set in the middle of the table. Now, browse the } \\
\text { Data Cards to find types of data that can help you achieve your } \\
\text { goals for your Persona and Themes. You may select up to three } \\
\text { Data Cards. } \\
\text { Approach 2) on the Data Canvas. Fill up the canvas and discuss: } \\
\text { here be customers' customers?) } \\
\text { n would customers want to use this service?) } \\
\text { aborate in the service? Who will develop and deliver the service?) } \\
\text { g this service or ethical issues to consider) }\end{array}$ \\
\hline
\end{tabular}

\section{FINDINGS}

\subsection{Overall experiences of the students}

Overall, students were able to follow the instructions without much confusion and actively engaged in group discussions throughout both sessions. During our focus group interview, students mentioned that this was their first time learning how to use data, especially open data as materials for designing new services. Students reflected that before being introduced to Datastorming, they were only familiar with "using data to understand something, not to generate something” (Student - 'S' hereinafter -_LN), or how data could only be "used to further improve a service [as feedback]" (S_SH). Other students also shared how they previously only saw data "to be more used in the backend operations" (S_JL) or "data used as an art piece to make art” (S_TE). As such, Datastorming broadened students' perspectives on how data can be used to design new services, going beyond backend operations or visualization purposes only.

Comparing the data-driven and human-driven approaches, the students felt more uncertain when trying to browse and combine different Data Cards with the data-driven approach. They seemed more comfortable with the human-driven approach as they could identify the persona and themes first, which is more similar to their usual way of working in the human-centered design process. Another reason might be because the students have already played Datastorming once (the first session with data-driven approach) and are more comfortable in the second session.

Encouraging healthy lifestyle was a popular subject among the teams. During the first round using the data-driven approach, five out of six teams' design goals were related to promoting active lifestyle and more health-conscious choices. This is reflected in the commonly used Data Cards, which are also relating to personal data on health and wellness (e.g. number of steps, heart rate, health monitor) or open data on location of sport facilities (e.g. parks, gyms, SportSG amenities). A reason could be that students felt uncertain to ideate from various data sets provided, thus started to pick the data sets that were familiar to them, which were related to topics such as healthcare, sustainability, or community building. Additionally, they might have gravitated to healthcare-related themes as it is an area where personal data plays a clear role.

The service concepts created from the human-driven approach were relatively more diverse than the first round using data-driven approach. The most popular Data Card in this round was "time spent on specific activities", which is a personal data that the teams applied to a variety of contexts from personal development, to traffic management, to social change. Students also found the visual design 
of the Data Cards useful, as mentioned by one of the students that "everything was visualized on the cards, making it easy to see and understand" (S_LN). Another student (S_KL) mentioned that the key information broken down on the Data Cards, like the category of data set, frequency of update, and duration of data collected helped his team quickly discern the usefulness of each data set.

\subsection{Creative connections through hands-on mix-and-match}

Each Data Card contains content that differs from one another, such as the source of the data (open data or personal data) and data format (numeric, geographic, etc.). Despite the complexity from the differences, the students were able to explore various combinations of data by tangibly mixing and matching different Data Cards together. As reflected by a student, "with data laid out on the cards, physicality allowed for interaction and made it easier to move and think with data" (S_LN). In addition, the game rules also encouraged the students to try out various combinations of data for inspiration. In the data-driven approach, the students randomly combined cards from both open data and personal data that may not usually interact with each other and framed non-analytical use of the cards to generate ideas through forced association. A student reflected: "the rules forced us to use data that we did not think of using before, we tried to forcefully associate personal data with open data to create new ideas" (S_SH). This let them explore potential links between data from different sources and categories. For example, they made links between infrastructure (data on location of parks) to people's health (data on gyms and number of steps) and started to ideate on how they could incentivize a healthy lifestyle. The environment Data Card then inspired them to come up with a campaign for a more sustainable and healthier lifestyle, where people are encouraged to go green by recycling trash while going for a walk at parks or when they are headed to gyms.

During the play, the students were also seen grouping cards in their hands and on the table as they made connections, in a type of short-term memory storage while they focused on evaluating other cards. It seems that the cards acted as physical markers in lengthy exchanges within the team, enabling easy retrieval of ideas and thoughts for insights [35]. The combination of clear texts and visuals in the Data Cards also made such interaction and exchange possible, as it allowed the cards to be viewed individually and in combination. The students physically moved the various Data, Theme and Persona Cards to assist continual negotiations between the grouped cards and potential new cards, where they tried to evaluate data for its relevance in contexts and make connections for new insights to ideate further.

\subsection{Making sense of data in contexts}

As the students browsed through the Theme Cards and Persona Cards provided, they were able to identify relevant situations that could benefit from the selected data sets. For example, the data could be used as a resource to optimize existing services (e.g. "Air passenger arrivals" data for managing the traffic flow at the customs checkpoint), be made accessible for end users to make informed decisions (e.g. "Carpark availability" data for deciding whether to drive or use public transport), or be used as a nudge to encourage desired behaviours (e.g. "Weekly time spent on social media" data for reducing screen time, "Number of steps" data for promoting healthy lifestyle, etc.).

In the session of the human-driven approach, the students started with the Persona Cards and Theme Cards that they found relatable or interesting, and mapped different data sets to find new meanings of data in the selected contexts. Finding new meanings and roles of data in the contexts led them to frame new design opportunities. For example, the Persona Cards ("'Kiasu - a Hokkien term that means afraid of losing out - Singaporean", "hawkers") and the Theme Cards ("self-development", "healthier lifestyle") selected by one student team, help them build the context around Singaporeans who are eager to stay productive, develop culinary skills and lead healthier lifestyle. This led to them selecting the Personal Data Card, "time spent on specific activities", and adding to the blank card a new data, "traditional food recipes", that is available as an open data, to support their service concept. The materials such as Theme Cards or Persona Cards helped to set the contexts, and the game rules encouraged the students to identify new meanings of data in the contexts.

\subsection{Facilitating collaborative data interpretation}

Turn-taking, which is part of the game rules for Datastorming, facilitated a collaborative exploration into data where every team member shared the rationale for their own card combination and built on each other's set of narratives. For example, a student in a team picked the transport Data Card ("Air passenger arrivals") and the lifestyle Data Card ("Time spent on specific activities") to draw a connection as to how time that could be better spent, was wasted due to delayed flights. Another student in the same team then built on the narrative with an environment Data Card ("Rainfall") he had on hand, explaining that data on the weather could have helped better inform flight schedules and thus, improve time management. Following on, another student suggested using data on traffic flow to make travel journeys smoother, which led to the service concept of a traffic monitoring service that monitors weather and helps travelers manage their time. By doing so, the students addressed the interpretations of data held by different team members and worked together to ideate on a service concept. In this process, Data Cards helped the students articulate their ideas and served the role as a shared visual reference among team members.

\subsection{Critical reflection through Data Canvas}

By referring to the prompts on each section of the Data Canvas, the students were reminded to look at the usage of data more critically, consider factors that may or may not work, how different stakeholders would come into play and identify missing sources of data. As mentioned by one student, "the canvas makes us look at the ideas more wholly to see if we are missing anything" (S_JL). Another student explained that the data canvas is "good to evaluate ideas to see if it [service concept] is feasible, especially to the stakeholders, we did not think who would develop the service, the canvas prompts us to rethink" (S_SH). On the other hand, the students also started to reconsider if all the Data Cards selected are relevant to their 
proposed service concept. The students explained that sometimes, out of excitement, they tried to include too many Data Cards in a service concept. They reflected that "too much [data sets] and it [service concept] gets too complex that it loses its goal" (S_TE). The Data Canvas then helped them relook at their ideas more holistically and prioritize the data sets used according to the main goal of the service.

\section{DISCUSSION}

Our findings show how Datastorming could enable design students who have little experience with 'service design based on data [39]', to make creative connections between different types of data, find new meanings of data by contextualizing it, and apply critical analysis when developing them into service concepts. In this section, we discuss how Datastorming helps introduce creative data literacy to design students by supporting their designerly way of doing $[10,18]$. We also review the limitations of the Datastorming method and the future development needs.

\subsection{Designerly way of working with Data}

By crafting abstract data into hands-on design materials and creating an environment for generative thinking, we found that the Datastorming method supported some of the core aspects of the designerly way of doing, namely visual and tangible explorations, synthetic thinking and solution-oriented thinking [10, 13, 18]. First, we speculate that the physical representation of various types of data was the key driver for students' ideation. As Huron et al. [17] explain, the cards seemed to provide the students with a quick entry point to working with data. When thinking with data, the Data Cards worked as "tinkering" materials [31] for the students to tangibly interact with different types of cards to ponder on their meanings and possibilities. This supported students' hands-on exploration of data as materials for ideation, like they usually do with paper, wood, or clay [31, 32]. The Data Cards also eased social interaction involving idea communication, idea negotiation and idea development and selection among team members as they enabled direct manipulation and configuration to support design moves that can be seen by everyone in the team. In the words of Lucero et al. [23], "the cards act as physical carriers of ideas". Such benefit of physical artefacts for collaborative work has been discussed by Vaajakallio and Mattelmäki's work on design game [40] and Buur and Soendergaard's work on video card game [6] and we too found similar benefits in the context of working with data.

Secondly, as illustrated in our findings, the physical cards and the game rules of Datastorming allowed the students to make connections among various types of data and draw new insights from the connections. How they group and regroup different types of data through physical actions and collaborative sense making is similar to how affinity diagrams or mood boards are created by designers to let new meanings emerge. Such actions and processes allowed design students' synthetic thinking [19] with data.

Lastly, the students were able to quickly evaluate, re-evaluate and revisit various Data Cards and ideas, to discern their usefulness in a design and gain quick inspirations for a new design space. This suggests that the cards enabled a "combination of visual cues, position cues and movement cues" [9] to recall meaning for identification of links and relevance [7, 34]. Also, the game rules facilitated constructive, solution-oriented thinking [10] of the design students and steered them towards the generation of new ideas from data, going beyond just understanding the data. The game rules imbued a playfulness in working with data as it "deliberately forces us to work with very obscure data sets" (S_KL) and make the students "come up with crazy ideas" (S_SH). This resulted in the discovery of novel ideas and design spaces. The Data Canvas provided the students with a more holistic and evaluative framework to review their ideas.

\subsection{Introducing Creative Data Literacy to Design students}

By supporting the designerly way of working with data, the Datastorming method provides a setting for design students to experience what it is like to create new design ideas inspired by data. Within a short timeframe (two sessions of 45 minutes each), the students were able to comprehend meanings and possible roles of data from the Data Cards and relate the data to contexts, while proceeding with the Datastorming play. They were able to explore various types of data and their connections in an open-ended manner. They compared, combined, and discerned relevant data sets to discover new meanings and envision potential design spaces. The ability to comprehend data, open-endedly explore data, and draw new meanings and insights from data, are what have been highlighted as abilities for creative data literacy $[03,11]$ or creative data work in the design process [20]. More importantly, the design students in this study learned that data can be used as design materials to inspire new design opportunities, without the need for a high level of technical skills in data analysis. The students reflected a change in mindset on the roles of data in the design process as they "realized that it [data] is intertwined with everyday lives, such that it can be connected to come up with new services" (S_TN). It also encouraged them to consider the use of data in subsequent design projects as the method "broadened [their] horizon" (S_KL). To teach creative data literacy to design students, we believe that this kind of mind-set change and reducing mindset barriers at the first entry point is critical. Based on the literature review and the experiment with Datastorming, we draw a few recommendations on how to introduce creative data literacy to design students as follow:

- Learning activity should be designed by supporting design students' familiar way of thinking and doing, i.e. by crafting data into creative design materials for their explorations;

- Learning activity should start with data sets or topics that are relatable or meaningful to students;

- Learning to use data should occur at the same time as learning about a design subject, for example, in our case, service design;

- Learning activity should include rules for focused engagement (e.g. game rules of the Datastorming) but leave them open for reinterpretation to encourage creativity and to find a meaningful focus (e.g. Data Canvas, trading of cards, blank cards). 


\subsection{Limitation and future development needs}

Datastorming is mainly targeted to be used for the early phase of designing with data, which shares the common focus with Kun et al.'s Exploratory Data Inquiry Framework (Figure 1) [20]. In terms of the Exploratory Data Inquiry Framework, Datastorming in this study mainly supports the phases of data exploration and data analysis, out of the five different phases. The first two phases, data acquisition and wrangling, were already provided by the current design of our method, through the pre-selection of data sets and the information design for the Data Cards. While blank cards were provided for students to add new data types as discovered necessary, they were not actively used.

For a more holistic coverage of creative data literacy, future designs of Datastorming could include activities related to data acquisition and wrangling, by giving students preliminary tasks of collecting various data types and making the Data cards on their own based on a given template. This preliminary task can be a useful sensitizing activity [37] for students to boost their interests and familiarity to data before the workshop. The actual workshop can then start with the students introducing their own Data Cards to their team members, which could help in ice-breaking and on boarding [1]. To integrate the data reporting phase [20], the Data Canvas could include segments that help students plan on how to report and represent data for identified target audiences and contexts. Also, group discussions around the ethical use of data were carried out in the converging phases through the Data Canvas. More emphasis on ethics and data security can be incorporated in the earlier stage of the gameplay, so that the service concepts are built with more robust considerations regarding the use of data.

The pilot study was carried out in a student workshop setting with all teams attempting the data-driven approach before the human-driven approach. To verify our observations on the limits of one approach as compared to the other, future work should look at counter-balancing the conditions with half the teams doing one condition and the other half doing the other condition.

The Datastorming kit presented in this paper contains Data Cards that are based on Singapore government's open data. In the future, the Datastorming kit could be designed to be more customizable and scalable for various contexts, for example, by providing templates or algorithms to easily create new sets of Data Cards for different projects. In fact, all Datastorming materials are currently open source, publicly available and downloadable from https://www. servicedesignlab.net/data-canvas-for-service-design for anyone to utilize and provide feedback on.

\section{CONCLUSION}

This paper introduces a method called Datastorming, aimed at teaching creative data literacy to design students who have little experience with data-driven design. Datastorming has been designed to support students' designerly way of working with data, by crafting abstract data into design materials and facilitating synthetic and solution-oriented thinking, rather than technical analysis of data. With the physical data cards that enable tangible explorations of various ideas, and design game rules that drive idea creation, students were able to design new services with data. We believe a method like Datastorming can provide an engaging entry point for students to learn what roles data can play in their creative work and how they can create innovative ideas enabled by data. With the current rise of data-driven design, design methods and tools to integrate thinking and working with data as part of the design process, should be continuously explored. As presented in this study, Datastorming attempts to be part of this exploration.

\section{ACKNOWLEDGMENTS}

We are grateful to the students in Division of Industrial Design, National University of Singapore, for their participation and contribution. We would also like to thank Esli Ee who made a major contribution to the development of the Datastorming kit. This research was supported by the Singapore Ministry of Education Academic Research Fund (R-290-000-012-114).

\section{REFERENCES}

[1] Moaddi M Almethhib. 2009. The Impact of Ice Breaking Exercises on Trainees' Interactions and Skill Acquisition: An Experimental Study. Economics and Administration 23.

[2] Basak Alper, Nathalie Henry Riche, Fanny Chevalier, Jeremy Boy and Metin Sezgin. 2017. Visualization literacy at elementary school. In Proceedings of the 2017 CHI Conference on Human Factors in Computing Systems, 5485-5497.

[3] Rahul Bhargava, Ricardo Kadouaki, Emily Bhargava, Guilherme Castro and Catherine D'Ignazio. 2016. Data murals: Using the arts to build data literacy. The Journal of Community Informatics 12 .

[4] Sander Bogers, Janne van Kollenburg, Heleen Rutjes, Eva Deckers, Joep Frens and Caroline Hummels. 2018. A showcase of data-enabled design explorations. In Extended Abstracts of the $2018 \mathrm{CHI}$ Conference on Human Factors in Computing Systems, 1-4.

[5] Eva Brandt. 2006. Designing exploratory design games: a framework for participation in participatory design? In Proceedings of the ninth conference on Participatory design: Expanding boundaries in design-Volume 1, 57-66.

[6] Jacob Buur and Astrid Soendergaard. 2000. Video card game: an augmented environment for user centred design discussions. In Proceedings of DARE 2000 on Designing augmented reality environments, 63-69.

[7] Ellahe Chabani and Bernhard Hommel. 2014. Effectiveness of visual and verbal prompts in training visuospatial processing skills in school age children. Instructional Science 42, 995-1012.

[8] Priscilla Cheung-Nainby and John Lee. 2018. Transformative Learning: co-design with communities' collective imagery as data for social innovation.

[9] Simon Clatworthy. 2011. Service innovation through touch-points: Development of an innovation toolkit for the first stages of new service development.

[10] Nigel Cross. 1982. Designerly ways of knowing. Design studies 3, 221-227.

[11] Catherine D'Ignazio. 2017. Creative data literacy: Bridging the gap between the data-haves and data-have nots. Information Design Journal 23, 6-18

[12] Amalia De Götzen, Péter Kun, Luca Simeone and Nicola Morelli. 2018. Making sense of data in a service design education. In Service Design and Innovation Conference: Proof of Concept Linköping University Electronic Press, 177-188.

[13] Kees Dorst. 2015. Frame innovation: Create new thinking by design. MIT press.

[14] Muriel Foulonneau, Sébastien Martin and Slim Turki. 2014. How open data are turned into services? In International Conference on Exploring services science Springer, 31-39.

[15] Muriel Foulonneau, Slim Turki, Géradine Vidou and Sébastien Martin. 2014. Open data in service design. Electronic Journal of e-Government 12, 99.

[16] Trine Heinemann, Stella Boess, Jeanette Landgrebe, Robb Mitchell and Maurice Nevile. 2011. Making sense of "things": developing new practices and methods for using tangible materials in collaborative processes. In Proceedings of the Procedings of the Second Conference on Creativity and Innovation in Design, Eindhoven, Netherlands2011 Association for Computing Machinery, 221-225.

[17] Samuel Huron, Pauline Gourlet, Uta Hinrichs, Trevor Hogan and Yvonne Jansen. 2017. Let's Get Physical: Promoting Data Physicalization in Workshop Formats. In Proceedings of the 2017 Conference on Designing Interactive Systems, 1409-1422.

[18] Jon Kolko. 2010. Abductive thinking and sensemaking: The drivers of design synthesis. Design issues 26, 15-28.

[19] Jon Kolko. 2011. Exposing the magic of design: A practitioner's guide to the methods and theory of synthesis. Oxford University Press.

[20] Peter Kun, Ingrid Mulder, Amalia De Götzen and Gerd Kortuem. 2019. Creative Data Work in the Design Process. In Proceedings of the 2019 on Creativity and Cognition, 346-358. 
[21] Susan Leigh Star. 2010. This is Not a Boundary Object: Reflections on the Origin of a Concept. Science, Technology, \& Human Values 35, 601-617. Accessed from: https://journals.sagepub.com/doi/abs/10.1177/0162243910377624 $10.1177 / 0162243910377624$

[22] Susan M Letourneau, ChangChia James Liu, Kaitlin Donnelly, Delia Meza, Stephen Uzzo and Katherine McMillan Culp. 2020. Museum makers: Family explorations of data science through making and exhibit design. Curator: The Museum Journal 63, 131-145.

[23] Andrés Lucero, Peter Dalsgaard, Kim Halskov and Jacob Buur. 2016. Designing with cards. In Collaboration in creative design Springer, 75-95.

[24] Mark Lycett. 2013. 'Datafication': making sense of (big) data in a complex world Taylor \& Francis.

[25] Patrizia Marti, Carl Megens and Caroline Hummels. 2016. Data-enabled design for social change: two case studies. Future Internet 8,46 . Accessed

[26] Viktor Mayer-Schönberger and Kenneth Cukier. 2013. Big data: A revolution that will transform how we live, work, and think. Houghton Mifflin Harcourt.

[27] Keegan McBride, Gerli Aavik, Maarja Toots, Tarmo Kalvet and Robert Krimmer 2019. How does open government data driven co-creation occur? Six factors and a 'perfect storm'; insights from Chicago's food inspection forecasting model. Government Information Quarterly 36, 88-97.

[28] Nicola Morelli, Amalia De Götzen and Luca Simeone. 2018. A system of innovation to activate practices on open data: The Open4Citizens project. In Conference on Smart Learning Ecosystems and Regional Development Springer, 99-109.

[29] Nicola Morelli, Ingrid Mulder, Janice S Pedersen, Tomasz Jaskiewicz, Amalia De Götzen and Marc Arguillar. 2017. Open Data as a New Commons. Empowering citizens to make meaningful use of a new resource. In International Conference on Internet Science Springer, 212-221.

[30] Juhani Pallasmaa. 2009. The thinking hand: Existential and embodied wisdom in architecture. Wiley Chichester.

[31] Stefano Parisi, Valentina Rognoli and Marieke Sonneveld. 2017. Material Tin kering. An inspirational approach for experiential learning and envisioning in product design education. The Design Journal 20, S1167-S1184.

[32] Owain Pedgley, Valentina Rognoli and Elvin Karana. 2016. Materials experience as a foundation for materials and design education. International Journal of
Technology and Design Education 26, 613-630.

[33] Alison Prendiville, Ian Gwilt and Val Mitchell. 2017. Making sense of data through service design-opportunities and reflections. Designing for Service, Key Issues and New Directions, 227-236.

[34] Eli Saltz and Suzanne Donnenwerth-Nolan. 1981. Does motoric imagery facilitate memory for sentences? A selective interference test. Journal of Verbal Learning and Verbal Behavior 20, 322-332

[35] Orit Shaer and Eva Hornecker. 2010. Tangible user interfaces: past, present, and future directions. Now Publishers Inc.

[36] Government of Singapore. 2011. Data.gov.sg. Accessed from: https://data.gov.sg

[37] Sacha Stoloff, Maude Boulanger, Virginie Roy and Marie-Claude Rivard. 2015. Sensitization Sessions as the Foundation for Training Transformation Activities. Journal of Education and Learning 4, 146-154.

[38] Milka Trajkova, A'aeshah Alhakamy, Francesco Cafaro, Rashmi Mallappa and Sreekanth R Kankara. 2020. Move your body: Engaging museum visitors with human-data interaction. In Proceedings of the 2020 CHI Conference on Human Factors in Computing Systems, 1-13.

[39] Slim Turki and Muriel Foulonneau. 2015. Service innovation: the hidden value of open data. Share-PSI 2.0 Krems Workshop: A self-sustaining business model for open data. Retrieved: $05 / 21$

[40] Kirsikka Vaajakallio and Tuuli Mattelmäki. 2014. Design games in codesign: as a tool, a mindset and a structure. CoDesign 10,63-77.

[41] Sarah Williams, Erica Deahl, Laurie Rubel and Vivian Lim. 2014. City Digits: Local Lotto: Developing Youth Data Literacy by Investigating the Lottery. Journal of Digital Media Literacy.

[42] Annika Wolff, Michel Wermelinger and Marian Petre. 2019. Exploring design principles for data literacy activities to support children's inquiries from complex data. International Journal of Human-Computer Studies 129, 41-54.

[43] Eliane Zambon Victorelli, Julio Cesar Dos Reis, Heiko Hornung and Alysson Bolognesi Prado. 2020. Understanding human-data interaction: Literature review and recommendations for design. International Journal of Human-Computer Studies 134, 13-32. 